Traffic Injury Prevention

\title{
Potential Occupant Injury Reduction in the U.S. Vehicle Fleet for Lane Departure Warning Equipped Vehicles in Single Vehicle Crashes
}

\section{Online Supplement}

\author{
Kristofer Kusano, Ph.D. \\ Virginia Tech \\ 440 Kelly Hall, 325 Stanger St (MC 0194) \\ Blacksburg, VA 24061 \\ kusano@vt.edu \\ Thomas I. Gorman \\ Virginia Tech Transportation Institute \\ 3500 Transportation Research Dr \\ Blacksburg, VA 24061 \\ gormani@vtti.vt.edu
}

Rini Sherony

Toyota Engineering \& Manufacturing North America, Inc.

1555 Woodridge Ave

Ann Arbor, MI 48105

rini.sherony@tema.toyota.com

Hampton C. Gabler, Ph.D.

Virginia Tech

445 Kelly Hall, 325 Stanger St (MC 0194)

Blacksburg, VA 24061

gabler@vt.edu 


\section{APPENDIX A: ADDITIONAL FIGURES}

This appendix shows additional graphics to accompany the paper.

Figure 1 shows how the three characteristics points were chosen from a normal distribution. To account for variability in the estimates of the missing variables, 3 values of departure velocity, departure angle, and radius of curvature were predicted for each NASS/CDS case. For a given NASS/CDS case, the regression models were used to generate a value for each missing variable. The resulting value was used as the mean and the root mean squared error (RMSE) of the regression model was used as the standard deviation to form a normal probability distribution function for the missing variable in the case. For the simulation case set, 3 values were chosen that represented the $17^{\text {th }}, 50^{\text {th }}$, and $83^{\text {rd }}$ percentiles of the distribution. These percentiles were chosen as characteristic points of three equal area portions under the normal probability density function

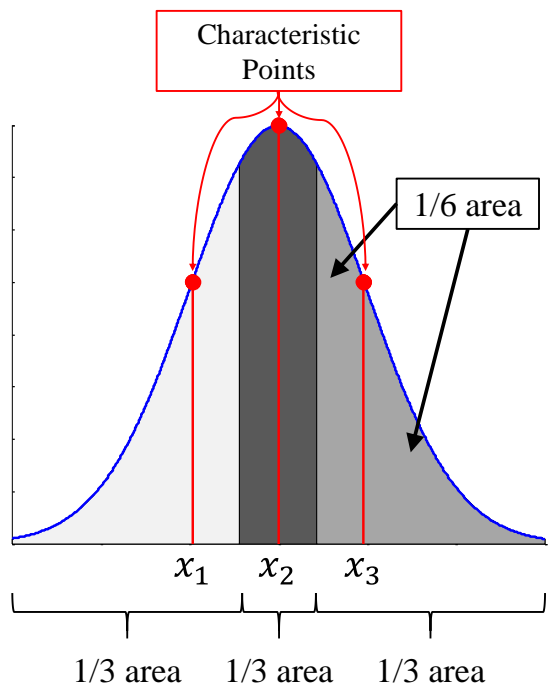

Figure 1. Selection of Characteristic Points from Normal PDF for Missing Variables.

Figure 2 shows how the roadside was discretized in to zones, index by k, for the probability of a crash model.

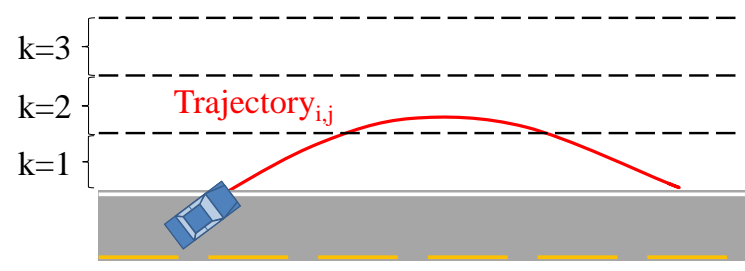

Figure 2. Simulation of Vehicle Off-Road Trajectory.

Figure 3, Figure 4, and Figure 5 show the cumulative distribution of departure velocity, departure angle, and radius of curvature, respectively, used in the simulations with percentiles of the distributions listed. 


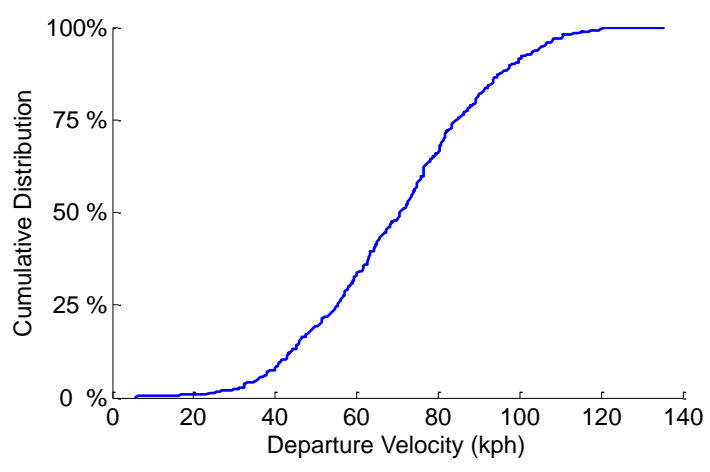

\begin{tabular}{|c|c|c|}
\hline $15^{\text {th }}$ Percentile & $50^{\text {th }}$ Percentile & $85^{\text {th }}$ Percentile \\
\hline $45.9 \mathrm{kph}$ & $70.8 \mathrm{kph}$ & $93.4 \mathrm{kph}$ \\
\hline
\end{tabular}

Figure 3. Cumulative Distribution of Departure Velocity in Simulations of LDW Benefits from NASS/CDS 2012 ( $n=21,882$ simulations).

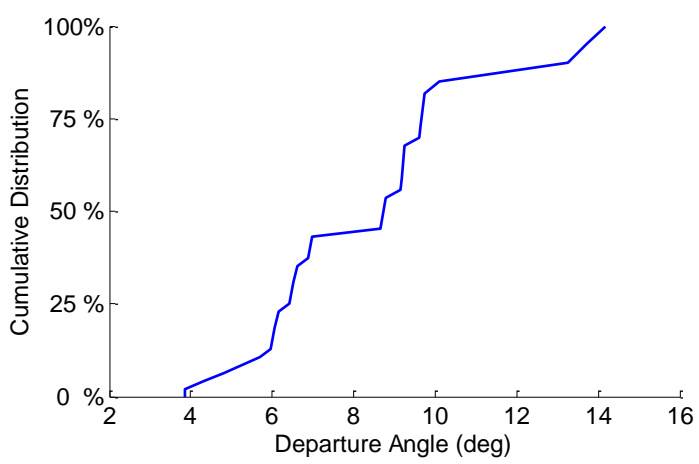

\begin{tabular}{|c|c|c|}
\hline $15^{\text {th }}$ Percentile & $50^{\text {th }}$ Percentile & $85^{\text {th }}$ Percentile \\
\hline $6.0^{\circ}$ & $8.7^{\circ}$ & $10.1^{\circ}$ \\
\hline
\end{tabular}

Figure 4. Cumulative Distribution of Departure Angle in Simulations of LDW Benefits from NASS/CDS 2012 ( $n=21,882$ simulations).

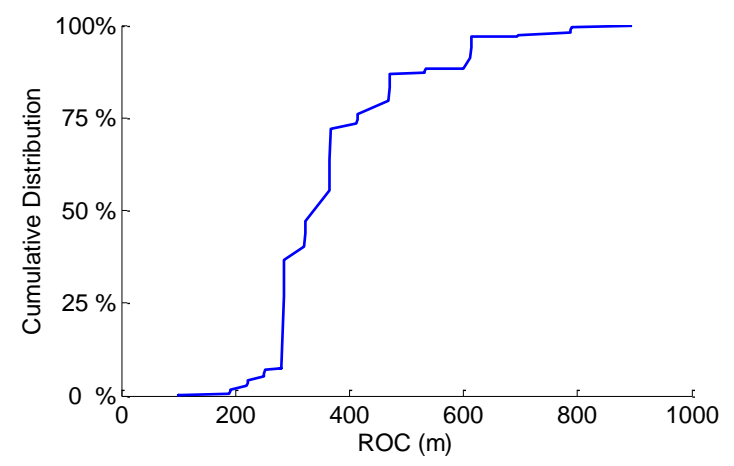

\begin{tabular}{|c|c|c|}
\hline $15^{\text {th }}$ Percentile & $50^{\text {th }}$ Percentile & $85^{\text {th }}$ Percentile \\
\hline $282 \mathrm{~m}$ & $337 \mathrm{~m}$ & $470 \mathrm{~m}$ \\
\hline
\end{tabular}

Figure 5. Cumulative Distribution of Radius of Curvature in Simulations of LDW Benefits from NASS/CDS 2012 ( $n=\mathbf{2 1 , 8 8 2}$ simulations). 
Figure 6 shows the effectiveness of LDW by shoulder width categories. Only simulations that had no adjacent travel lanes crossed prior to departure, i.e. traveling in rightmost or leftmost lane, are shown in Figure 6 Error! Reference source not found.to isolate the effect of shoulder width. Roads with a shoulder width of 0 had no effectiveness, while a $0.3 \mathrm{~m}$ shoulder had low effectiveness. Larger shoulders, especially in simulations with the largest shoulder category, benefited greatly from LDW.

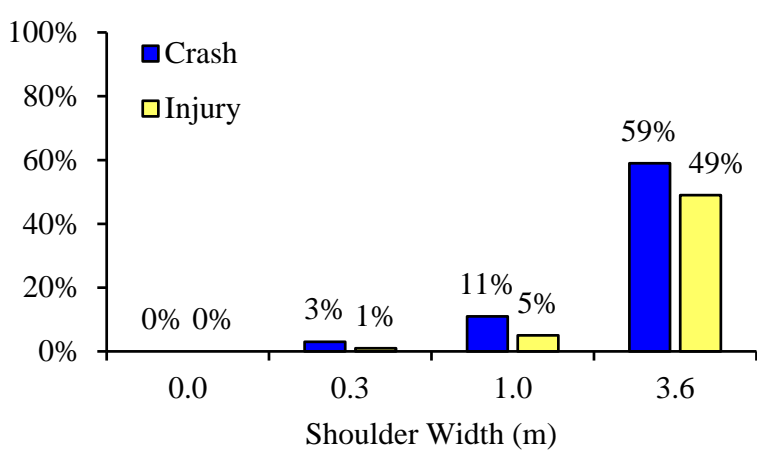

Figure 6. Effectiveness of LDW for NASS/CDS 2012 by Shoulder Width ( $n=16,920$ simulations). 


\section{APPENDIX B: REGRESSION MODELS FOR MISSING DEPARTURE CONDITIONS}

\section{Objective}

The objective of this appendix is to detail multiple linear regression models for departure velocity, departure angle, and radius of curvature (ROC) were developed using the NCHRP 17-22 data. These multiple linear regression were used to predict the most probable values of velocity, angle, and ROC from a sampled of NASS/CDS crashes.

\section{Methodology}

Model formulation was done using Adjusted $\mathrm{R}^{2}$ to compare predictive value between different candidate models. Adjusted $\mathrm{R}^{2}$ penalizes the addition of terms to a model, whereas the standard $\mathrm{R}^{2}$, mathematically, can only increase as terms are added to a model even if those terms contribute nothing. Outlier diagnostics were also performed, including residual plots for patterns (e.g. non-uniformity) that might indicate problems and the Cook's D influence metric to identify highly influential observations. Cook's D is a metric which is computed for each observation used in a regression and indicates how much the regression is changed by the removal of that observation. Any observations with a Cook's D greater than 1.0, a the standard rule-of-thumb for Cook's D, or with a Cook's D significantly higher than all other observations, were removed from potential regressions to evaluate the robustness of the model.

The goal of the outlier diagnostics is to ensure that a few extreme points are not completely dominating the regression analysis, i.e. that the models are robust against outliers. High influence points identified by residual plots and/or Cook's D metric were removed from the regressions to determine their effect on the regression coefficients. The regression was robust if the regression coefficients did not have large changes with and without the high influence points.

One feature of the modeling approach for velocity, angle, and ROC was to develop multiple tiers of models for each missing parameter. Cases in NASS/CDS have varying degrees of missing data for variables. Therefore, models that use a large number of predictors or use predictors that are often missing cannot be used for all cases. Our approach was to fit between 1 and 3 tiers of models, with the first tier using the most descriptive but also possibly having the most missing variables. The subsequent tiers used fewer and more commonly used variables. The goal is that at least one model can be applied to all NASS/CDS cases in the sample.

\section{Results}

Selected Cases: Table 1 summarizes the selected cases used for each model. The model for departure velocity used all available cases in the database. In contrast, the departure angle model only used drift out of lane departure crashes. Those crashes caused by control loss may have had higher departure angles than those drift out of lane crashes. The ROC model was restricted to cases that occurred on curved road sections as described by the coded NASS/CDS road alignment variable. Additionally, ROC was to restricted to those below $9000 \mathrm{~m}$. The data contains a number of extremely large ROC values for curved roads, i.e. a very slight curve. One possible explanation for these extremely large ROC measurements is inaccuracies in the middle ordinate methodology used to compute ROC on the scene. The investigators would lay a straight tape line across a curved road section to form 
a chord along the arc. Next, the investigators would measure the distance from the tape to the lane marking at the middle of the chord. Using trigonometry, the ROC can be computed from these two measurements. In a very slight curve, the middle ordinate will be very small and thus small inaccuracies in middle ordinate could have caused a large change in ROC. These extremely large ROC values will influence regression models greatly. A threshold of $9000 \mathrm{~m}$ was chosen because it is the $99^{\text {th }}$ percentile of the ROCs measured in the NCHRP 17-22 data.

Table 1. Selected Cases from NCHRP 17-22 Database for Each Multiple Linear Regression Model.

\begin{tabular}{|l|c|c|c|}
\hline Model & Exclusion Criteria & N & Freq. \\
\hline All NCHRP 17-22 Crashes & - & 875 & 279,300 \\
\hline Departure Velocity & All Departures & 875 & 279,300 \\
\hline Departure Angle & Drift out of lane departures only, exclude control loss & 137 & 35,988 \\
\hline Radius of Curvature (ROC) & Curved road alignment, ROC < 9000 m & 268 & 86,197 \\
\hline
\end{tabular}

The case sets in Table 1 were used as starting points for the developed models. The actual models for some variables were fit with less cases because any cases with a missing value for the predictors were excluded.

Departure Velocity Models: The model parameters for the Tier 1 departure velocity model are listed in Table 2, with the p-value for the test for a null coefficient. By conventions, if the p-value is less 0.05 that model parameter is statistically significant, i.e. likely not equal to zero. Not all model parameters included in the tier 1 model were less than 0.05 but were included in the model because of the variability in the crash data.

Table 2. Model Parameters and p-values (in parentheses) for Coefficients for Tier 1 Departure Velocity Model ( $\left.v_{D}\right)$

\begin{tabular}{|c|c|c|c|}
\hline \multicolumn{2}{|l|}{$\begin{array}{ll} & \text { Parameters } \\
\end{array}$} & $v_{D}(1)$ & p-value \\
\hline \multicolumn{2}{|l|}{ Intercept $(\mathrm{km} / \mathrm{h})$} & 27.61 & 0.1121 \\
\hline \multirow{2}{*}{ Police Reported Travel Speed $(\mathrm{km} / \mathrm{h})$} & $\begin{array}{l}\text { Concrete/ Asphalt Surface } \\
\text { Type }\end{array}$ & 0.2900 & 0.0060 \\
\hline & Dirt/Gravel Surface Type & 0.1166 & 0.2682 \\
\hline \multirow{2}{*}{ One-Way/Divided Highway, 1 lane } & Dry Road Surface & 12.10 & 0.0547 \\
\hline & Wet/Snow Road Surface & -8.95 & 0.3272 \\
\hline \multirow{2}{*}{ One-Way/Divided Highway, 2 lanes } & Dry Road Surface & 24.20 & 0.0002 \\
\hline & Wet/Snow Road Surface & 18.08 & 0.0309 \\
\hline \multirow{2}{*}{$\begin{array}{l}\text { One-Way/Divided Highway, } 3 \text { or } \\
\text { more lanes }\end{array}$} & Dry Road Surface & 18.09 & 0.0189 \\
\hline & Wet/Snow Road Surface & 35.85 & $<0.0001$ \\
\hline \multirow{2}{*}{ Undivided Highway, 2 lanes } & Dry Road Surface & 12.45 & 0.0409 \\
\hline & Wet/Snow Road Surface & 5.01 & 0.5651 \\
\hline Undivided Highway, 3 or more lanes & Dry road surface & 0 & - \\
\hline \multicolumn{2}{|l|}{ Posted Speed Limit (kph) } & 0.155 & 0.2444 \\
\hline \multicolumn{2}{|l|}{ Driver Unbelted } & 8.24 & 0.0196 \\
\hline \multicolumn{2}{|c|}{ Driver Belted } & 0 & - \\
\hline \multicolumn{2}{|c|}{ Crash occurred between 2:00 AM to 5:00 AM } & -7.48 & 0.1514 \\
\hline \multicolumn{2}{|c|}{ All other Times of Day } & 0 & - \\
\hline \multicolumn{2}{|l|}{ Number of Cases } & 278 & \\
\hline \multicolumn{2}{|l|}{ Frequency } & 96,858 & \\
\hline \multicolumn{2}{|l|}{ Adjusted $\mathrm{R}^{2}$} & 0.4761 & \\
\hline \multicolumn{2}{|l|}{ Root Mean Squared Error (RMSE) } & 17.637 & \\
\hline
\end{tabular}


Residual analysis discovered two high-influence points for the improved tier 1 regression. Exclusion of these observations resulted in only modest changes to the regression, indicating that the model is likely fairly robust. The values in Table 2 for the tier 1 model reflect the regression performed without these high-influence points.

Table 3 summarizes the model coefficients and p-values for the tier 2 model. The model is similar than the tier 1 model, except it excludes police reported travel speed. Police reported travel speed is often missing in NASS/CDS crashes.

Table 3. Model Parameters and p-values (in parentheses) for Coefficients for Tier 2 Departure Velocity Model ( $\left.v_{D}\right)$

\begin{tabular}{|c|c|c|c|}
\hline \multicolumn{2}{|c|}{ Parameters } & $v_{D}(2)$ & p-value \\
\hline \multicolumn{2}{|c|}{ Intercept $(\mathrm{km} / \mathrm{h})$} & -65.78 & 0.0324 \\
\hline \multicolumn{2}{|c|}{ Posted Speed Limit (kph) } & 1.535 & $<0.0001$ \\
\hline \multicolumn{2}{|c|}{ One-Way/Divided Highway, 1 lane } & 73.29 & 0.0473 \\
\hline \multicolumn{2}{|c|}{ One-Way/Divided Highway, 2 lanes } & 86.16 & 0.0304 \\
\hline \multicolumn{2}{|c|}{ One-Way/Divided Highway, 3 or more lanes } & 70.02 & 0.2071 \\
\hline \multicolumn{2}{|c|}{ Undivided Highway, 2 lanes } & 97.89 & 0.0027 \\
\hline \multicolumn{2}{|c|}{ Undivided Highway, 2 lanes } & 0 & - \\
\hline \multirow{5}{*}{$\begin{array}{l}\text { Posted Speed Limit } \\
(\mathrm{km} / \mathrm{h})\end{array}$} & One-Way/Divided Highway, 1 lane & -0.9874 & 0.0170 \\
\hline & One-Way/Divided Highway, 2 lanes & -1.0190 & 0.0206 \\
\hline & $\begin{array}{l}\text { One-Way/Divided Highway, } 3 \text { or more } \\
\text { lanes }\end{array}$ & -0.8741 & 0.1102 \\
\hline & Undivided Highway, 2 lanes & -1.1728 & 0.0024 \\
\hline & Undivided Highway, 2 lanes & 0 & - \\
\hline \multicolumn{2}{|c|}{ Dry Surface Condition } & 8.137 & 0.0368 \\
\hline \multicolumn{2}{|c|}{ Wet Surface Condition } & 0 & - \\
\hline \multicolumn{2}{|c|}{ Concrete/Asphalt Road Surface } & 10.982 & 0.0010 \\
\hline \multicolumn{2}{|c|}{ Dirt/Gravel Road Surface } & 0 & - \\
\hline \multicolumn{2}{|c|}{ Driver Unbelted } & 12.932 & $<0.0001$ \\
\hline \multicolumn{2}{|c|}{ Driver Belted } & 0 & - \\
\hline \multicolumn{2}{|c|}{ Crash occurred between 2:00 AM to 5:00 AM } & -14.355 & $<0.0001$ \\
\hline \multicolumn{2}{|c|}{ All other Times of Day } & 0 & - \\
\hline \multicolumn{2}{|l|}{ Number of Cases } & 812 & \\
\hline \multicolumn{2}{|l|}{ Frequency } & 261,172 & \\
\hline \multicolumn{2}{|c|}{ Adjusted $\mathrm{R}^{2}$} & 0.2860 & \\
\hline \multicolumn{2}{|c|}{ Root Mean Squared Error (RMSE) } & 19.760 & \\
\hline
\end{tabular}

Finally, Table 4 shows the tier 3 model that depends only on the road configuration, road surface type, and crash time of day. These three variables are available in virtually all NASS/CDS crashes. 
Table 4. Model Parameters and p-values (in parentheses) for Coefficients for Tier 3 Departure Velocity Model ( $v_{D}$ )

\begin{tabular}{|l|c|c|}
\hline \multicolumn{1}{|c|}{ Parameters } & $\boldsymbol{v}_{\boldsymbol{D}} \mathbf{( 3 )}$ & p-value \\
\hline Intercept (km/h) & 66.09 & $<0.0001$ \\
\hline One-Way/Divided Highway, 1 lane & -4.979 & 0.6953 \\
\hline One-Way/Divided Highway, 2 lanes & 11.269 & 0.1608 \\
\hline One-Way/Divided Highway, 3 or more lanes & 7.058 & 0.4623 \\
\hline Undivided Highway, 2 lanes & -0.669 & 0.9274 \\
\hline Undivided Highway, 2 lanes & 0 & - \\
\hline Concrete/Asphalt Road Surface & 12.89 & $<0.0001$ \\
\hline Dirt/Gravel Road Surface & 0 & - \\
\hline $\begin{array}{l}\text { Crash occurred between 2:00 AM to 5:00 } \\
\text { AM }\end{array}$ & -11.20 & $0 . .0309$ \\
\hline All other Times of Day & 0 & - \\
\hline & & \\
\hline Number of Cases & 854 & \\
\hline Frequency & 274,000 & \\
\hline Adjusted R & 0.1265 & \\
\hline Root Mean Squared Error (RMSE) & 21.603 & \\
\hline
\end{tabular}

Departure Angle Model: A model was identified that predicted departure angle based upon driver seat belt status, initial departure side, and roadway type as shown in Table 5. The natural logarithm transformation for the departure angle was used in the model to preserve normality. All model parameters had significant p-values, suggesting the coefficients in the model are unlikely zero. Having an unbelted driver, departing on the right side, and driving on a divided roadway increase the departure angle. A single model could be used for departure angle because none of the simulated cases from NASS/CDS 2012 had missing values for the variables used in the model.

Table 5. Model Parameters and p-values for Coefficients for Departure Angle Model $\left(\theta_{D}\right)$

\begin{tabular}{|l|c|c|}
\hline \multicolumn{1}{|c|}{ Parameters } & Coefficients & p-value \\
\hline Intercept (Ln(degrees)) & 1.859 & $<0.0001$ \\
\hline Driver Unbelted & 0.407 & 0.002 \\
\hline Driver Belted & 0 & - \\
\hline Initial Departure side Right & 0.353 & 0.0474 \\
\hline Initial Departure side Left & 0 & - \\
\hline Undivided Roadway & -0.393 & 0.0064 \\
\hline Divided Roadway & 0 & - \\
\hline & & \\
\hline Number of Cases & 129 & \\
\hline Frequency & 32,206 & \\
\hline Adjusted R & 0.3339 & \\
\hline $\begin{array}{l}\text { Root Mean Squared Error } \\
\text { (RMSE) }\end{array}$ & 0.5482 & \\
\hline
\end{tabular}

Radius of Curvature Models: Table 6 summarizes the two enhanced model developed for ROC. The natural logarithm transformation was used for ROC to preserve normality. In the tier 1 ROC model, higher speed limits led to slightly larger ROCs. The smallest ROCs, i.e. tightest curves, mostly occurred on highway off-ramps. Therefore, if the traffic flow description was a one lane divided highway the radius of curvature was much smaller than for all other road types. One high influence point was excluded from the dataset based upon a high Cook's D coefficient. 
This observation greatly affected the regression coefficients. This low $\mathrm{R}^{2}$ value is more a reflection of the small number of cases and does not necessarily imply the model has no value in predicting ROC. Almost all NASS/CDS cases have a posted speed limit, thus the Tier 2 model will be used for only $0.2 \%$ of simulated crashes from NASS/CDS 2012.

Table 6. Model Parameters and p-values for Coefficients for Tier 1 and Tier 2 Radius of Curvature (ROC)

\begin{tabular}{|l|c|c|c|c|}
\hline \multicolumn{1}{|c|}{ Parameters } & ROC(1) & p-value & ROC(2) & p-value \\
\hline Intercept (Ln(m)) & 3.856 & $<0.0001$ & 5.541 & $<0.0001$ \\
\hline Posted Speed Limit (kph) & 0.0157 & 0.0516 & - & - \\
\hline Not one lane on a divided highway & 1.167 & $<0.0001$ & 0.853 & 0.0001 \\
\hline One lane on a divided highway & 0 & - & 0 & - \\
\hline & & & & \\
\hline Number of Cases & 262 & & 265 & \\
\hline Frequency & 80,798 & & 81,675 & \\
\hline Adjusted R & & & 0.04347 & \\
\hline Root Mean Squared Error (RMSE) & 0.07083 & & 1.189 & \\
\hline
\end{tabular}

